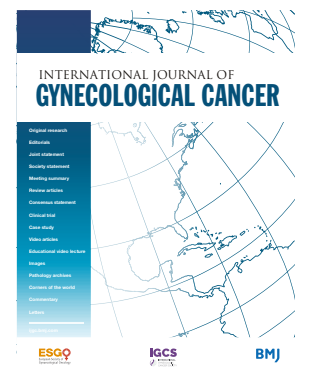

For numbered affiliations see end of article.

\section{Correspondence to} Professor Denis Querleu, Dipartimento Scienze della Salute della Donna e del Bambino, Fondazione Policlinico Universitario A Gemelli IRCCS, 00168 Roma, Italy; denis. querleu@esgo.org

$\mathrm{DD}$ is deceased

Accepted 4 December 2020 Published Online First 15 January 2021

\section{How to make a vaginal cuff before laparoscopic radical hysterectomy}

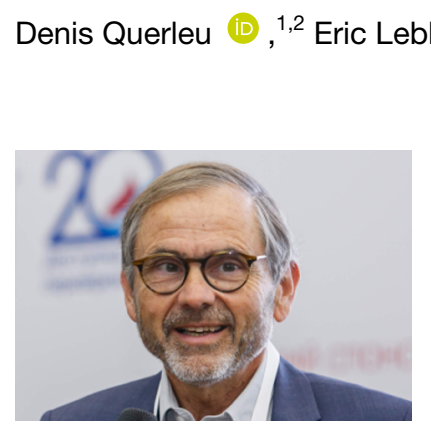

\begin{abstract}
Denis Querleu
1 Dipartimento Scienze della Salute della Donna e del Bambino, Fondazione Policlinico Universitario A Gemelli IRCCS, Rome, Italy

${ }^{2}$ Department of Gynecology, University Hospital, Strasbourg, France
\end{abstract}

Biography: Denis Querleu is a gynecologic oncologist, ESG0 past president. He has been during his career head of the gynecologic oncology division at the Lille (France) Oscar Lambret Comprehensive Cancer Center, professor of oncology and head of the department of surgery at the Toulouse (France) Comprehensive Cancer Center, professor and head of the department of obstetrics and gynecology at McGill university in Montreal (Canada)
One of the basic principles of surgical oncology is to avoid spilling active tumor cells in a healthy potential host area. A striking demonstration of this principle is available in the case of ovarian tumors. ${ }^{1}$ This is crucial at the time of laparoscopic radical hysterectomy, and possibly applies to open radical hysterectomy as well.

The no-spillage principle was implemented from the beginning by the founders of cervical cancer surgery themselves. Schauta and Wertheim used to close the vagina before removing cervical cancer vaginally or abdominally, respectively. ${ }^{2}$ The publications in this journal of the results of a German monocentric study ${ }^{3}$ and of the European SUCCOR study ${ }^{4}$ strongly suggest that meeting this principle is a possible way to overcome the detrimental effect of the laparoscopic approach in cervical cancer observed in the only available randomized controlled study addressing this issue. ${ }^{5}$ Closure of the vaginal cuff appears to be a potentially efficient

\title{
How to make a vaginal cuff before laparoscopic radical hysterectomy
}

Denis Querleu, Eric Leblanc, Daniel Dargent ${ }^{\dagger}$

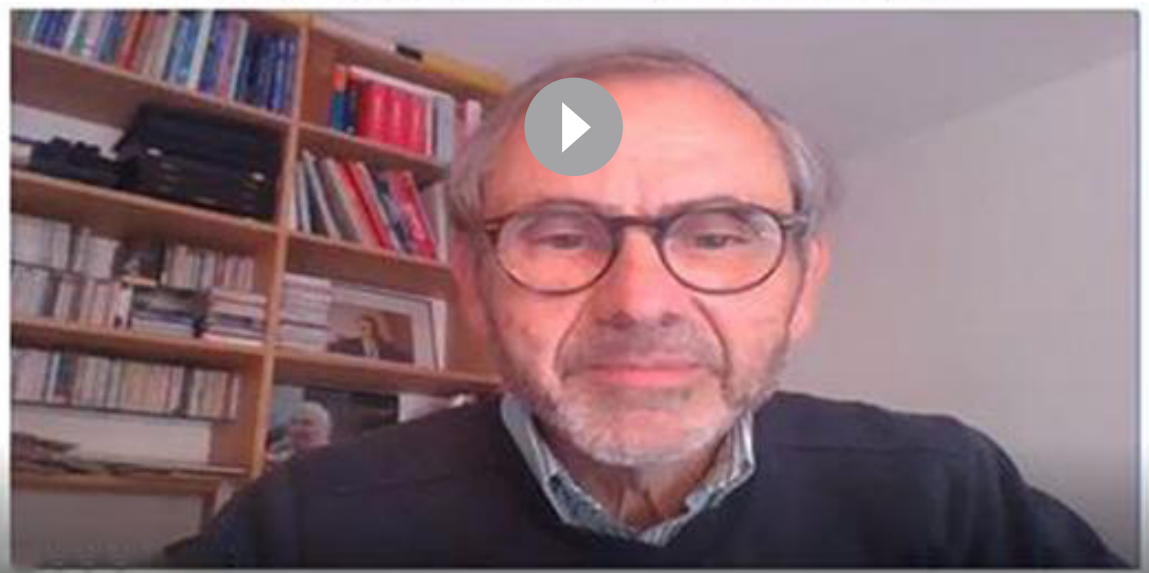

Video 1 Closure of the vaginal cuff with Chrobak (or similar) forceps. Two Chrobak forceps have been placed in the midline, joining the ventral and dorsal edge of the vaginal cuff. Laterally, the cuff is still open. The edges are grabbed with Kocher forceps 
way to confine the tumor and prevent the contamination of the peritoneum and of the pelvic tissues by active tumor cells.

The technique was described more than one century $a g 0^{6}$ and has not substantially changed since the pioneer era. An English language translation of the precise and comprehensive description of the surgical steps in the German language atlas of vaginal surgery by Reiffenstuhl and Platzer is available. ${ }^{7}$ In France, radical vaginal surgery was taught by the late Daniel Dargent, whose memory is still alive years after his passing away, justifying his position as last author of this article.

This educational video lecture illustrates the steps of making a vaginal cuff: identification of the adequate incision line at a distance from the tumor, placement of 6-8 Kocher forceps inside the incision line, infiltration with saline serum or diluted epinephrine of the vaginal fold created by traction on the Kocher forceps, vaginal incision using cold knife or electrosurgery, minimal separation of the bladder and rectum, and closure of the vaginal cuff using Chrobak type forceps. In the setting of radical vaginal trachelectomy or hysterectomy, the operation continues vaginally. In the setting of laparoscopic radical hysterectomy, suturing of the vaginal cuff, placement of stay sutures, and packing of the vagina precede the laparoscopic steps. The same may also apply to abdominal radical hysterectomy. Alternately, the vaginal cuff can be made at the end of the laparoscopic or open procedure before opening of the vagina.

Three different videos of the same procedure by each of the three authors are intentionally presented in order to illustrate different clinical situations, individual preferences, and tips and tricks to deal with difficulties, most of them encountered in case of narrow vagina.

Primary making of the vaginal cuff has the dual advantage of enclosing the tumor and of defining the best adapted incision line avoiding both insufficient margins and excessive removal of vaginal tissue. The technique is not difficult to master and can be incorporated in all approaches for cervical cancer surgery.

\section{Author affiliations}

${ }^{1}$ Dipartimento Scienze della Salute della Donna e del Bambino, Fondazione Policlinico Universitario A Gemelli IRCCS, Rome, Italy

${ }^{2}$ Department of Gynecology, University Hospital, Strasbourg, France

${ }^{3}$ Department of Surgery, Centre Oscar Lambret, Lille, France

${ }^{4}$ University of Lyon, Lyon, France

Contributors DQ: conception, editing, surgical video. EL: surgical video. DD: surgical video.

Funding The authors have not declared a specific grant for this research from any funding agency in the public, commercial, or not-for-profit sectors.

Competing interests None declared.

Patient consent for publication Not required.

ORCID iD

Denis Querleu http://orcid.org/0000-0002-3984-4812

\section{REFERENCES}

1 Vergote I, De Brabanter J, Fyles A, et al. Prognostic importance of degree of differentiation and cyst rupture in stage I invasive epithelial ovarian carcinoma. Lancet 2001;357:176-82.

2 Bader AA, Bjelic-Radisic V, Tamussino KF, et al. Recurrence in a Schuchardt incision after Schauta-Amreich radical vaginal hysterectomy for cervical cancer. Int J Gynecol Cancer 2006;16:1479-81.

3 Kohler C, Hertel H, Herrmann J, et al. Laparoscopic radical hysterectomy with transvaginal closure of vaginal cuff - a multicenter analysis. Int J Gynecol Cancer 2019;29:845-50.

4 Chiva L, Zanagnolo V, Querleu D, et al. SUCCOR study: an international European cohort observational study comparing minimally invasive surgery versus open abdominal radical hysterectomy in patients with stage IB1 cervical cancer. Int J Gynecol Cancer 2020;30:1269-77.

5 Ramirez PT, Frumovitz M, Pareja R, et al. Minimally invasive versus abdominal radical hysterectomy for cervical cancer. N Engl J Med 2018;379:1895-904.

6 Schauta F. Die ertweiterte vaginale totalexstirpation des uterus bei kollumkarzinom. Verlag von Josef $A F \check{r}$, Wien and Prague, 1908.

7 Reiffenstuhl G, Platzer W. Atlas of vaginal surgery, volume 1. surgical anatomy and technique. Urban and Schwarzenberg, Berlin, 1974. 